\title{
Whatever
}

or

\section{As You Like It, Part Two}

While the alcoholic department chair is squeezing your thorax, you remember the answer to number eleven on the quiz about Egypt you took in the fifth grade. The word scarab comes to mind, and that's what he looks like-a desiccated entomological specimen carved in stone. You think, what if God ended the world at this very moment? Frozen, the breath in your throat is like an elephant in the herd of a grand maharaj killed one morning by a freak tornado from Borneo or Nepal. Miss Harriet Nichiguchi was your teacher, but that was long ago on O'ahu, and he's not really strangling you, but it feels like it. Pop quiz-why are you sitting here anyway? Think of the million other stupid things you could be doing: shopping for dust, perfecting that ulcer, watching Joan Crawford's kabuki mask crack on TV. 